\title{
Integrated cardiovascular/respiratory control in type 1 diabetes evidences functional imbalance : Possible role of hypoxia
}

\section{Bianchi, L.}

2017-10-01

Bianchi , L, Porta , C , Rinaldi , A, Gazzaruso , C , Fratino , P , DeCata , P , Protti , P , Paltro , R \& Bernardi , L 2017 , ' Integrated cardiovascular/respiratory control in type 1 diabetes evidences functional imbalance : Possible role of hypoxia ' , International Journal of Cardiology , vol. 244 , pp. 254-259 . https://doi.org/10.1016/j.jjcard.2017.06.047

http://hdl.handle.net/10138/298258

https://doi.org/10.1016/j.jjcard.2017.06.047

publishedVersion

Downloaded from Helda, University of Helsinki institutional repository.

This is an electronic reprint of the original article.

This reprint may differ from the original in pagination and typographic detail.

Please cite the original version. 


\title{
Integrated cardiovascular/respiratory control in type 1 diabetes evidences functional imbalance: Possible role of hypoxia
}

\author{
L. Bianchi ${ }^{a}$, C. Porta ${ }^{\text {a }}$, A. Rinaldi ${ }^{\text {a }}$, C. Gazzaruso ${ }^{\text {b }}$, P. Fratino ${ }^{\text {b }}$, P. DeCata ${ }^{\text {b }}$, P. Protti ${ }^{\text {a }}$, R. Paltro ${ }^{\text {a }}$, L. Bernardi ${ }^{\text {a,c, }}$, \\ a Department of Internal Medicine, University of Pavia, Pavia, Italy \\ ${ }^{\mathrm{b}}$ Department of Internal Medicine and Endocrinology, IRCCS Fondazione S.Maugeri, Pavia, Italy \\ c Folkhälsan Institute of Genetics, Folkhälsan Research Center, University of Helsinki, Helsinki, Finland
}

\section{A R T I C L E I N F O}

\section{Article history:}

Received 22 December 2016

Received in revised form 9 May 2017

Accepted 12 June 2017

Available online 15 June 2017

\section{Keywords:}

Chemoreflex

Baroreflex

Diabetic neuropathy

Hypoxia

Autonomic nervous system

Type 1 diabetes

\begin{abstract}
A B S T R A C T
Background: Cardiovascular (baroreflex) and respiratory (chemoreflex) control mechanisms were studied separately in diabetes, but their reciprocal interaction (well known for diseases like heart failure) had never been comprehensively assessed. We hypothesized that prevalent autonomic neuropathy would depress both reflexes, whereas prevalent autonomic imbalance through sympathetic activation would depress the baroreflex but enhance the chemoreflexes.

Methods: In 46 type- 1 diabetic subjects ( $7.0 \pm 0.9$ year duration) and 103 age-matched controls we measured the baroreflex (average of 7 methods), and the chemoreflexes, (hypercapnic: ventilation/carbon dioxide slope during hyperoxic progressive hypercapnia; hypoxic: ventilation/oxygen saturation slope during normocapnic progressive hypoxia). Autonomic dysfunction was evaluated by cardiovascular reflex tests.

Results: Resting oxygen saturation and baroreflex sensitivity were reduced in the diabetic group, whereas the hypercapnic chemoreflex was significantly increased in the entire diabetic group. Despite lower oxygen saturation the hypoxic chemoreflex showed a trend toward a depression in the diabetic group.

Conclusion: Cardio-respiratory control imbalance is a common finding in early type 1 diabetes. A reduced sensitivity to hypoxia seems a primary factor leading to reflex sympathetic activation (enhanced hypercapnic chemoreflex and baroreflex depression), hence suggesting a functional origin of cardio-respiratory control imbalance in initial diabetes.
\end{abstract}

@ 2017 Elsevier B.V. All rights reserved.

\section{Introduction}

In diabetes, the impairment in autonomic function is associated with increased morbidity and mortality [1]. This abnormality could be observed at an early stage by a depressed baroreflex sensitivity [2,3], which is also a well-established marker of cardiovascular mortality for cardiovascular causes [4,5].

Abbreviations: BRS, baroreflex sensitivity; $\mathrm{CO}_{2}$ t, end-tidal carbon dioxide pressure; DLCO, diffusing capacity of the lung for carbon monoxide; $\mathrm{FEV}_{1}$, forced expiratory volume (at the end of the first second of forced expiration); FVC, forced vital capacity; HIF-1, hypoxia-inducible factor-1; HVR, hypoxic chemoreflex (ventilatory response); HCVR, hypercapnic chemoreflex (ventilatory response); HRV, heart rate variability; $\mathrm{N}+$ subgroup, presence of incipient autonomic dysfunction; N- subgroup, absence of autonomic dysfunction; SDNN, standard deviation of all RR intervals; T1D, type-1 diabetic subjects; VE, minute ventilation; Vt, tidal volume; $\mathrm{VT}-\mathrm{CO}_{2}$, ventilatory threshold for carbon dioxide; CXCR4, C-X-C chemokine receptor type 4; eNOS, endothelial nitric oxide synthase; EPC, endothelial progenitor cells; GLO-1, glyoxalase-1; GSH, glutathione; MGO, methylglyoxal; ROS, reactive oxygen species; SDF-1, CXCR4-ligand stromal cellderived factor-1; VEGF, vascular endothelial growth factor.

* Corresponding author at: Folkhälsan Research Center, Biomedicum Helsinki (C318b), PO Box 63, FIN-00014, University of Helsinki, Finland.

E-mail address: lbern1ps@unipv.it (L. Bernardi).
Recent data from our laboratory suggests that the baroreflex abnormality could be to some extent functional, and evidences point to similarities to the more general dysregulation occurring in congestive heart failure [6,7]. In chronic heart failure, a reduced baroreflex and a sympathetic overactivity, are linked to an overactivity of the reflexes that regulate ventilation (chemoreflexes), in a clear inverse relationship [8]. These functional abnormalities are implicated in the reduced exercise performance, and interventions aimed at restoring the cardio-respiratory control (e.g. physical exercise) improved both cardiovascular regulation and exercise tolerance, hence resulting in important clinical improvement in patients with heart failure [9].

On the other hand, we previously found that severe autonomic damage (as it occurs in familial dysautonomia) is associated with a reduction in both chemo- and baroreflexes [10].

In diabetes the cardio-respiratory integrated control remains to a large extent to be investigated. Although several studies have tested the hypothesis of altered respiratory or cardiovascular control, the respiratory and cardiovascular reflexes were tested only in small number of subjects and only separately on chemoreflex (hypercapnic only [11], hypoxic only [12], both chemoreflexes [13]) or baroreflex 
[2,3]. Results were interpreted simply as yet another additional evidence of neuropathy and thus of little novelty.

Therefore, a comprehensive evaluation of cardiovascular, hypoxic and hypercapnic reflexes is missing so far, thus preventing us to understand how these reflexes might interact in diabetes.

This is particularly relevant in view of the previous hypothesis of an initially functional (hence reversible) autonomic abnormality in type 1 diabetes. In that case the different reflexes should be linked in a mutual reciprocal interaction, like in heart failure (e.g. ventilatory reflexes enhanced and cardiovascular reflexes depressed). Conversely, a generalized reduction in reflexes could be the result of an established neuropathy, as shown in familial dysautonomia [10].

In the present study we then evaluated the baroreflex sensitivity and the central and peripheral chemoreflex sensitivities in subjects with absent or minimal autonomic dysfunction (as evaluated by a standard battery of cardiovascular reflex tests). The type of the link should give us an indication of whether the extent of the possible abnormality should be interpreted. We reasoned that a generalized depression in both cardiovascular and respiratory reflexes could be an indication of autonomic neural damage (e.g. similar to familial dysautonomia), whereas an inverse relationship between cardiovascular and respiratory reflexes (depressed baroreflex and enhanced chemoreflex gain) would be an indication of functional disorder, eg similar to heart failure.

\section{Methods}

We studied 46 type- 1 diabetic subjects (T1D) ( $33 \pm 1$ year, 22 female) and 103 age-matched controls. Clinical characteristics of study participants are shown in Table 1.

Type 1 diabetes was defined as C-peptide deficiency $(<0.03 \mathrm{nmol} / \mathrm{l})$ and initiation of permanent insulin treatment within one year after the diagnosis of diabetes. None of the patients showed clinical signs of cardiovascular disease. Only two patients had antihypertensive medication (ACE-inhibitors). The healthy control subjects were recruited by email advertisements among university students and staff. Only individuals with normal fasting glucose and without 1 st degree relatives with diabetes mellitus were included. Before participation, all subjects gave their written informed consent. The study protocols were approved by the Ethics Committee of University of Pavia.

\subsection{Experimental set-up}

All subjects were investigated in a quiet room, at a temperature between 19 and $23^{\circ} \mathrm{C}$ between $8 \mathrm{a}$.m. and $2 \mathrm{p} . \mathrm{m}$. Before the examination, the subjects received instructions to refrain from alcohol for $36 \mathrm{~h}$, caffeinated beverages and cigarettes for $12 \mathrm{~h}$. A light mea was permitted $2 \mathrm{~h}$ before testing. Electrocardiogram was recorded using a bipolar precordial lead. Continuous blood pressure was monitored with validated [14] applanation tonometry (Colin CBM 7000, San Antonio, USA) from the wrist of the left arm held at

Table 1

Clinical characteristics of study participants (mean \pm standard error).

\begin{tabular}{|c|c|c|c|}
\hline & T1D & Controls & $\mathrm{p}$ value \\
\hline $\mathrm{N}$ & 46 & 103 & \\
\hline $\mathrm{M} / \mathrm{F}$ & $24 / 22$ & $52 / 51$ & ns \\
\hline Age (years) & $33.2 \pm 1.1$ & $36.4 \pm 1.4$ & ns \\
\hline Weight (Kg) & $63.1 \pm 1.5$ & $67.2 \pm 1.1$ & 0.025 \\
\hline Height (cm) & $167.1 \pm 1.4$ & $171.3 \pm 0.9$ & 0.008 \\
\hline Body mass index $\left(\mathrm{Kg} / \mathrm{m}^{2}\right)$ & $22.5 \pm 0.3$ & $22.9 \pm 0.3$ & ns \\
\hline Years from diagnosis & $7.0 \pm 0.9$ & - & \\
\hline $\mathrm{HbA1c}(\%)(\mathrm{mmol} / \mathrm{mol})$ & $\begin{array}{l}8.19 \pm 0.24 \\
66\end{array}$ & - & \\
\hline Fasting glucose (mg/dL) & $184.4 \pm 12.7$ & - & \\
\hline Diabetes complications & $\begin{array}{l}\text { Diabetic retinopathy: } \\
\text { Proliferative: } 2 \\
\text { Non-proliferative: } 6 \\
\text { Microalbuminuria: } 2\end{array}$ & - & \\
\hline Other pathologies & $\begin{array}{l}\text { Hypertension: } 2 \\
\text { Depressive sd.: } 1 \\
\text { H. Pylori gastritis: } 1 \\
\text { Hepatitis B: } 2 \\
\text { Hepatitis C: } 1 \\
\text { Hiatal hernia: } 1\end{array}$ & - & \\
\hline Medications & ACE-inhibitors: $2 \mathrm{pz}$ & - & \\
\hline Autonomic score & $0.8 \pm 0.1$ & $0.0 \pm 0.0$ & - \\
\hline
\end{tabular}

heart level. A respiratory signal (by inductive respiratory belts positioned around the chest), pulse oximetry (Ohmeda Pulse Oxymeter, Englewood, Colorado, USA) and carbon dioxide were also recorded (COSMOplus, Novametrix Wallingford, Connecticut, USA). All signals were acquired continuously on a personal computer (Apple Macintosh), at 300 samples/s/signal

\subsection{Autonomic testing}

The subjects underwent five cardiovascular autonomic function tests using previously described methods [15]: 1) the difference between expiratory and inspiratory heart rate during slow deep breathing (6 cycles per minute), 2) the maximum/minimum 30/15 ratio of RR interval during active standing, 3) the systolic blood pressure response to standing, and 4) the maximum/minimum ratio of RR interval during a Valsalva manoeuver, 5) the diastolic blood pressure increase during handgrip, obtained by compressing a sphygmomanometer cuff partially inflated and keeping a pressure of $30 \%$ of maximal strength for $2 \mathrm{~min}$.

\subsection{Baroreflex testing}

Electrocardiogram and continuous blood pressure were recorded in the supine position at rest during 5 min of spontaneous breathing, to measure baroreflex sensitivity (BRS).

\subsection{Chemoreflex testing}

During chemoreflex testing, the participants were seated, and connected to a rebreathing circuit through a mouthpiece, in a fashion similar to that previously described and validated $[16,17]$. Rebreathing into a closed circuit causes a progressive reduction in inspired oxygen and increase in carbon dioxide concentration, both of which stimulate ventilation. When the response to varying oxygen was to be assessed (hypoxic chemoreflex), end-tidal carbon dioxide pressure $\left(\mathrm{CO}_{2}\right.$ et) was kept constant at $40 \pm$ $1 \mathrm{~mm} \mathrm{Hg}$ by passing a portion of the expired air into a scrubbing circuit (containing soda lime) before returning it to the rebreathing bag.

Conversely, when the response to carbon dioxide was to be tested (hypercapnic chemoreflex), oxygen was continuously supplied at a very low flow $(1 \mathrm{l} / \mathrm{min})$ to the rebreathing circuit in order to maintain the percentage of arterial oxygen saturation $\left(\mathrm{SaO}_{2}\right)$ at baseline values (>95\%). The amount of air in the rebreathing circuit was set at $5 \mathrm{l}$, in order to maintain the duration of each test (and hence the individual's compliance) at about $7 \mathrm{~min}$. Before each rebreathing test, the subjects breathed room air through the same mouthpiece as during the rebreathing, in order to collect baseline data. The rebreathing tests terminated when $\mathrm{SaO}_{2}$ reached $80 \%$ (response to hypoxia) and when $\mathrm{CO}_{2}$ et reached $55 \mathrm{~mm} \mathrm{Hg}$ (response to hypercapnia) (Fig. 1). In each condition, we continuously measured the carbon dioxide via the COSMOplus connected to the mouthpiece and $\mathrm{SaO}_{2}$. The airway flow was measured continuously by a heated Fleish pneumotachograph (Metabo, Epalinges, Switzerland) connected to a differential pressure transducer (RS part N395-257, Corby, UK) connected in series in the expiratory arm of the rebreathing circuit.

\subsection{Assessment of baroreflex sensitivity and heart rate variability}

Previous studies have shown a poor correlation between different indices of BRS, while, on the other hand, no method has shown clear superior performance over the other [18]. Accordingly, we have used all the most common methods, and analysed the BRS as their average, as previously validated [19]. BRS was determined from the time series of RR interval and systolic blood pressure using the sequence method for 1) positive and 2) negative sequences, or spectral analysis for the 3) low frequency, 4) high frequency, and 5) for the average of the low- and high-frequency components, 6) the transfer function technique and 7) by the standard deviation method (BRS-SD), following the technical details previously explained [19]. Additionally, the standard deviation of all RR intervals (SDNN) was considered an index of global RR interval variability.

\subsection{Analysis of respiration/chemoreflex sensitivity}

The ventilatory flow signal was integrated by software and each breath was identified. Breathing rate, tidal volume (Vt) and minute ventilation (VE) relative to each breath were recognized, with their corresponding values of $\mathrm{SaO}_{2}$ and $\mathrm{CO}_{2}$ et.

The chemoreflex sensitivity to hypoxia (hypoxic ventilatory response) or hypercapnia (hypercapnic ventilatory response) was obtained from the slope of the linear regression line of minute ventilation plotted against $\mathrm{SaO}_{2}$ or $\mathrm{CO}_{2}$ et, respectively (Fig. 1). The change in ventilation due to hypercapnia is interpreted as the central chemoreflex sensitivity, whereas the change in ventilation due to hypoxia is interpreted as peripheral chemoreflex sensitivity. The point at which the ventilation started to increase during the progressive $\mathrm{HCVR}$ (called ventilatory threshold $\left(\mathrm{VT}-\mathrm{CO}_{2}\right.$, Fig. 1) was identified by interpolating the ventilation $/ \mathrm{CO}_{2}$ et plot using a fourth-order polynomial function.

\subsection{Statistical analysis}

Data are presented as mean \pm standard error. Differences were analysed by one-way ANOVA factorial design. If overall significant changes were observed $(p<0.05)$, then significance was tested by Sheffe's test. Correlation between different variables was evaluated by linear regression analysis. 
HYPOXIC (peripheral)
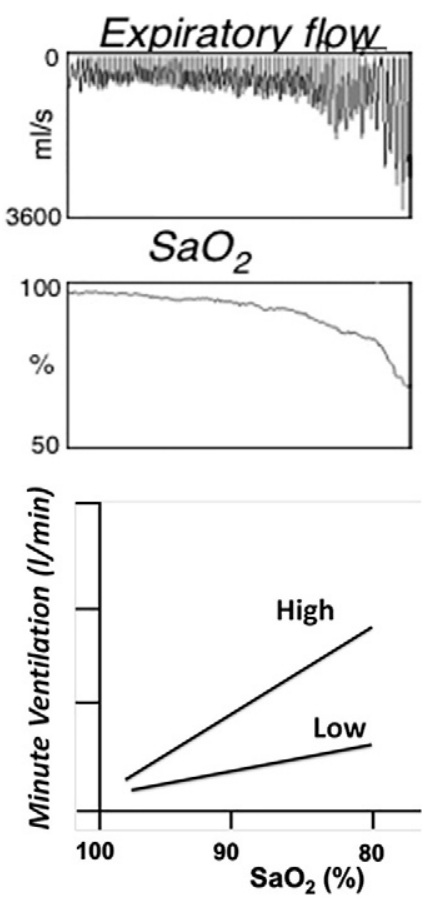

Progressive $\mathrm{O}_{2}$ reduction

\section{HYPERCAPNIC} (central)
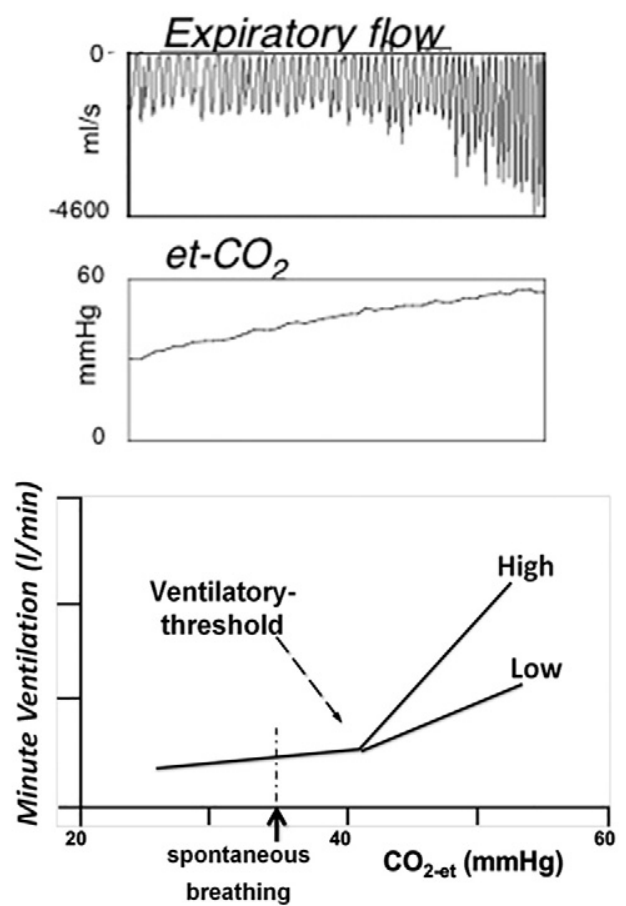

Progressive $\mathrm{CO}_{2}$ increase

\section{Chemoreflex $=$ slope of the relationship between ventilation $/ \mathrm{CO}_{2}$ or $\mathrm{O}_{2}$}

Fig. 1. Schematic measure of chemoreflex sensitivity using a rebreathing circuit to increase $\mathrm{CO}_{2}$ at a constant $\mathrm{FiO}_{2}$ or to decrease $\mathrm{FiO}{ }_{2}$ at a constant $\mathrm{CO}_{2}$.

\section{Results}

\subsection{Autonomic score}

The results obtained in the diabetic subjects are presented in Table 1. Mild signs of autonomic involvement were present in 26/46 subjects (average score $1.42 \pm 0.14$ ), and absent in $20 / 46$ patients. Five subjects presented 2 abnormal cardiovascular tests, and 3 subjects presented 3 abnormal cardiovascular tests [15].

\subsection{Cardiovascular data}

The results during $5 \mathrm{~min}$ of spontaneous breathing are shown in Table 2. RR interval (inter beat interval) was shorter in T1D compared to controls (T1D: $800 \pm 19$ vs controls: $865 \pm 13 \mathrm{msec}, \mathrm{p}<0.01$ ). Also SDNN was lower in T1D compared to controls ( $40.0 \pm 3.7$ vs $56.8 \pm$ $2.5 \mathrm{msec}, \mathrm{p}<0.005)$. No significant difference was seen in blood pressures between groups.

\subsection{Respiratory data}

The average results at rest during 5 min of spontaneous breathing are shown in Table 2. $\mathrm{SaO}_{2}$ was lower in T1D compared to controls (96.7 $\pm 0.1 \%$ vs $97.4 \pm 0.1 \%, \mathrm{p}<0.005)$. Conversely $\mathrm{CO}_{2}$ et was higher in T1D (40.3 $\pm 0.3 \mathrm{~mm} \mathrm{Hg}$ vs controls: $38.4 \pm 0.4 \mathrm{~mm} \mathrm{Hg}, \mathrm{p}<0.01)$. Ventilatory threshold was similar in each groups, but the difference between resting $\mathrm{CO}_{2}$ et and the ventilatory threshold was lower in T1D compared to controls $(2.4 \pm 0.3$ vs $4.3 \pm 0.5, \mathrm{p}<0.01)$. There was a tendency toward higher ventilation: VE, Vt and breathing rate were all slightly increased in T1D compared to controls.

\subsection{Baroreflex sensitivity}

Baroreflex sensitivity was reduced in the entire diabetic group ( $9.8 \pm 0.9$ vs controls: $13.4 \pm 0.8 \mathrm{~ms} / \mathrm{mm} \mathrm{Hg}, \mathrm{p}<0.01$ ) (Table 3 ).

\subsection{Chemoreflex sensitivity}

The hypoxic chemoreflex showed a trend toward a depression $\left(0.73 \pm 0.9\right.$ vs controls: $0.91 \pm 0.07 \mathrm{~L} / \mathrm{min} / \% \mathrm{SaO}_{2}$, p:ns) (Table 3 ).

Conversely, the hypercapnic chemoreflex was significantly increased in the entire diabetic group ( $1.86 \pm 0.19$ vs $1.41 \pm 0.13 \mathrm{~L} / \mathrm{min} / \mathrm{mm} \mathrm{HgCO}_{2}$ in controls, $\mathrm{p}<0.05$ ) (Table 3 ).

\section{Discussion}

\subsection{Main findings}

Our study shows for the first time to our knowledge that there exist a link between the abnormality in cardiovascular control and the abnormality in respiratory control in type 1 diabetes. We found in our T1D:

1. Low resting $\mathrm{SaO}_{2}$ and high $\mathrm{CO}_{2}$ et with a tendency toward higher ventilation compared to controls.

2. Depression in baroreflex and heart rate variability but enhanced "central" (hypercapnic) chemoreflex and not enhanced "peripheral" (hypoxic) chemoreflex. 
Table 2

Cardiovascular and respiratory data (mean \pm standard error).

\begin{tabular}{lll}
\hline Test & $\begin{array}{l}\text { Controls } \\
(\mathrm{N}=103)\end{array}$ & $\begin{array}{l}\text { T1D } \\
(\mathrm{N}=46)\end{array}$ \\
\hline RR (interbeat interval) msec & $865 \pm 13$ & $800 \pm 19^{* *}$ \\
RR stand deviation (SDNN) msec & $56.8 \pm 2.5$ & $40.0 \pm 3.7^{* * *}$ \\
SBP (systolic blood pressure) mm Hg & $113.8 \pm 1.8$ & $114.6 \pm 2.2$ \\
DBP (diastolic blood pressure) mm Hg & $63.1 \pm 1.5$ & $62.8 \pm 2.2^{*}$ \\
VE (minute ventilation) (L/min) & $10.9 \pm 0.5$ & $12.5 \pm 0.8$ \\
Vt (tidal volume) (ml) & $985 \pm 57$ & $1014 \pm 89$ \\
Breathing rate (/min) & $12.6 \pm 0.4$ & $13.9 \pm 0.6$ \\
$\mathrm{SaO}_{2}$ (\%) & $97.4 \pm 0.1$ & $96.7 \pm 0.1^{* * *}$ \\
$\mathrm{CO}_{2}$ et (end-tidal) (mm Hg) & $38.4 \pm 0.4$ & $40.3 \pm 0.3^{* *}$ \\
$\mathrm{CO}_{2}$ et at ventilatory threshold point (mm Hg) & $42.0 \pm 0.5$ & $42.7 \pm 0.39$ \\
Diff. (resting average $\mathrm{CO}_{2}$ et - Vent threshold) & $4.3 \pm 0.5$ & $2.4 \pm 0.3^{* *}$ \\
\hline
\end{tabular}

* $\mathrm{p}<0.05$ vs controls.

** $\mathrm{p}<0.01$ vs controls.

*** $\mathrm{p}<0.005$ vs controls.

These findings suggest that hypoxia due to insufficient hypoxic ventilatory stimulus leads to compensatory enhancement of central chemoreflex through sympathetic activation, which reduces the BRS and the heart rate variability. As a consequence, in our diabetic patients the cardio-respiratory control abnormalities (baro-chemoreflex) seem more likely the result of a functional alteration rather than anatomic neural lesions.

\subsection{Low $\mathrm{SaO}_{2}$ and high $\mathrm{CO}_{2}$ et with a tendency toward higher ventilation}

Diabetic patients showed lower resting $\mathrm{SaO}_{2}$ compared to controls (Table 2) despite a tendency toward higher ventilation (VE, Vt and breathing rate were all slightly increased). This apparently slight difference in $\mathrm{SaO}_{2}$ was never emphasized before, but it should be noted that due to the dissociation curve of hemoglobin, in the normoxic range even a small difference in $\mathrm{SaO}_{2}$ implies a large difference in $\mathrm{PaO}_{2}$. Furthermore, elevated blood $\mathrm{HbA}_{1} \mathrm{c}$ levels (as it was the case in our T1D patients) lead to an overestimation of $\mathrm{SaO}_{2}$ by $\mathrm{SpO}_{2}$ monitored with a pulse oximetry [21]. Thus, we can infer that diabetic patients have indeed a lower $\mathrm{PaO}_{2}$ compared to controls. The $\mathrm{PaO}_{2}$ is the input to the chemoreceptors, but despite this should represent a higher ventilatory stimulus, the hypoxic chemoreflex was not increased (or rather showed a trend toward a reduction) in our T1D patients. Our results therefore indicate a condition of relative hypoxemia in T1D.

Although many studies identified several possible mechanisms leading to hypoxia, so far this condition in diabetes has never been formally established. Different possible mechanisms could be involved.

Firstly, a reduced lung function (evaluated as low forced vital capacity, low forced expiratory volume in one second and abnormalities in diffusion capacity (DLCO) due to glycosylation of basal membranes) had been shown in diabetes. The reduced lung function was inversely related to blood glucose levels, duration of diabetes and its severity is independent of smoking or obesity [22,23]. some possible causes are: micro-angiopathy of the alveolar capillaries and pulmonary arterioles $[24,25]$, chronic low-grade tissue inflammation [26], autonomic neuropathy involving the respiratory muscles [27], loss of elastic recoil secondary to collagen glycosylation of lung parenchyma [28], hypoxia-

Table 3

Baro- and chemo- reflexes (mean \pm standard error).

\begin{tabular}{lll}
\hline Test & $\begin{array}{l}\text { Controls } \\
(\mathrm{N}=103)\end{array}$ & $\begin{array}{l}\mathrm{T} 1 \mathrm{D} \\
(\mathrm{N}=46)\end{array}$ \\
\hline Baroreflex sensitivity $(\mathrm{ms} / \mathrm{mm} \mathrm{Hg})$ & $13.4 \pm 0.8$ & $9.8 \pm 0.9^{* *}$ \\
Hypercapnic chemoreflex (central) $(\mathrm{L} / \mathrm{min} / \mathrm{mm} \mathrm{Hg})$ & $1.41 \pm 0.13$ & $1.86 \pm 0.19^{*}$ \\
Hypoxic chemoreflex (peripheral) $\left(\mathrm{L} / \mathrm{min} / \% \mathrm{SaO}_{2}\right)$ & $0.91 \pm 0.07$ & $0.73 \pm 0.08$ \\
\hline$* \mathrm{p}<0.05$. & & \\
$* * \mathrm{p}<0.01$. & & \\
\end{tabular}

induced insulin resistance [29]. Iozzo et al. found a significant decrease in the arterial partial pressure of $\mathrm{O} 2$ and in DLCO, with a significant increase in the alveolo-arterial gradient of $\mathrm{O} 2$ in patients with hypertriglyceridemia, a common condition in type 2 diabetes [30]. Among pathologies causing a "reduced lung function" obstructive sleep apnea syndrome might be particularly relevant. This condition is frequent in type 2 diabetic patients and the two conditions seem to occur in a bidirectional association: obstructive sleep apnoea, through the effects of intermittent hypoxaemia and sleep fragmentation, could stimulate insulin resistance, glucose intolerance, and type 2 diabetes. In reverse, type 2 diabetes might increase the predisposition to, or accelerate the progression of obstructive and central sleep apnoea, possibly through the development of peripheral neuropathy and abnormalities of ventilatory and upper airway neural control $[31,32,33]$. Additionally there is a decreased oxygen transport and transfer to the tissues, due not only to macro/microangiopathy but also to hemoglobin glycosylation that plays a role in regulating both erythrocyte metabolism and $\mathrm{Hb}-$ oxygen affinity. HbA1c shifts the dissociation curve of the hemoglobin to the left and decreases the p50 (partial pressure of oxygen at which $50 \%$ of hemoglobin is saturated with oxygen). A lower p50 values indicate increased $\mathrm{Hb}$-oxygen affinity and lower oxygen transfer to peripheral tissues $[34,35]$.

In diabetes there seems to be not only a hypoxic status but also an inadequate response to it, which also seems to start independently from neuropathy. Catrina et al. [36] demonstrated that both hyperglycemia and hypoxia play essential pathophysiological roles in the complications of diabetes, which may result from a defective response of the tissues to low oxygen tension. The hyperglycemia seems to blunt the function of hypoxia-inducible factor-1 (HIF-1), a transcription factor that is essential for adaptive responses of the cells to hypoxia. These findings were confirmed by Bento and Pereira [37] that suggested a molecular mechanism whereby methylglyoxal (MGO), which accumulates in high-glucose conditions, leads to a rapid proteasome-dependent degradation of HIF$1 \alpha$ (a labile subunit of HIF-1) under hypoxia. This impaired HIF- $1 \alpha$ regulation has several deleterious consequences, including decreased production of vascular endothelial growth factor (VEGF) and its receptor, C-X-C chemokine receptor type 4 (CXCR4) and CXCR4-ligand stromal cell-derived factor-1 (SDF-1) and decreased production and activity of endothelial nitric oxide synthase (eNOS). Other target genes include erythropoietin, glucose transporter 1-3 and lactate dehydrogenase-A. All of these genes and proteins are required for an appropriate response to hypoxia, being the driving forces of neovascularization, myocardial collateralization, wound healing, renal and neural function and endothelial progenitor cells (EPC) mobilization to injured areas [38]. Thus, a decrease in their levels has detrimental consequences for cell and tissue adaptation and survival at low oxygen levels, leading to complications such as diabetic retinopathy, poor wound healing, neuropathies, cardiovascular and renal diseases [38].

Thus, these findings together with those of the present study, suggest that in T1D there is a reduction in arterial and tissue oxygenation, possibly due to a pulmonary dysfunction not compensated by an enhanced hypoxic peripheral chemoreflex, possibly as a consequence of multiple cellular abnormalities (hyperglycemia, low-grade inflammation, oxidative stress), blunting the normal response to hypoxia.

\subsection{Enhanced "central" (hypercapnic) chemoreflex, but reduced baroreflex and heart rate variability}

Our results suggest for the first time an integrated view in the pathophysiologic mechanisms present in diabetes that links the hypoxia, as a "primum movens", with baro- and chemoreflexes dysfunction. In fact, the consequence of the reduced sensitivity to hypoxia would be a compensatory sympathetic activation leading to a stimulation of the hypercapnic central chemoreflex, but also to a depression of baroreflex, heart rate variability and autonomic function tests [39]. It is of note that, despite a high resting and-tidal $\mathrm{CO}_{2}$ levels (likely resulting from the 
mechanisms discussed above) the diabetic patients showed values very close to the ventilatory threshold for $\mathrm{CO}_{2}$, a finding that matched the increased central chemoreflex sensitivity. The fact that the threshold was similar as in the control group further confirmed that the sensitivity to $\mathrm{CO} 2$ was indeed not compromised. Thus, it seems that these alterations, rather than the consequence of neuropathy, likely suggest a more complex derangement of cardiorespiratory reflexes, which may eventually lead to neuropathy with time.

Our previous study indeed demonstrated that oxygen administration improves heart rate variability and BRS more in T1D than in controls [40]. The increased response to hyperoxia suggested a pre-existing condition of tissue hypoxia that functionally restrained parasympathetic activity in patients with type 1 diabetes [40]. Our present findings are also supported by most studies performed in diabetes, showing either abnormal ventilatory response to hypoxia with a preserved response to hypercapnia in type 2 diabetes [13] or a depressed baroreflex sensitivity [2,3], although in these previous studies in diabetes the possible link between these two essential reflexes was not considered and as a consequence the combination of cardiorespiratory control tests was not performed. A reciprocal interaction of baroreflex and peripheral chemoreflex, was seen in healthy volunteers [41] or in patients with cardiovascular disease $[8,42]$. Many relevant cardiovascular/respiratory diseases (e.g. heart failure, hypertension, chronic obstructive pulmonary diseases) exhibit potential vicious circles of reflex derangements [8]: the reduced cardiovascular control (baroreflex attenuation) interplays with increased breathing stimulation (chemoreflex augmentation) through a sustained sympathetic activation and a reduced vagal activity. The same reciprocal baro- and chemo-reflex interaction seen in T1D in the present study allowed us to suggest that the abnormalities observed could be the result of a functional imbalance rather than neuropathy, similar to what is already established in heart failure $[8,43]$. This is clinically important because a functional imbalance is in principle potentially reversible.

\subsection{Clinical implications}

The respiratory control alterations observed in the present study might result from reduced response to hypoxia, and lead to compensatory activation of hypercapnic chemoreflex (which in turn limits in part the extent of hypoxia) and sympathetic activity (which reduces heart rate variability, BRS, and the autonomic cardiovascular tests).

Respiratory control alterations could be important to worsen both the autonomic dysfunction and its consequences, e.g. by worsening exercise tolerance in diabetes, similarly to chronic congestive heart failure [44]. In turn, resting hypoxemia and sympathetic activation are important factors leading to low-grade systemic inflammation, reactive oxygen species accumulation (ROS) and oxidative stress $[31,45,46]$, which are well known to be involved in the pathophysiology of diabetes and most of its systemic complications $[47,48]$. The functional nature of this alteration, at least in early stages, suggest possible correcting factors aimed at adjusting respiratory control abnormalities, like physical activity, breathing control exercises, positive airway pressure treatment. Other potential interventions include drugs like Desferrioxamine and dimethyloxalylglycine, which both stabilize and activate HIF- $1 \alpha$, or gene transfer-based stabilization of HIF-1 $\alpha$ (adenovirus encoding a constitutively active form of HIF-1 $\alpha$ ) [49]. Our results warrant further researches that could identify new therapies for preventing diabetic complications.

Conclusion

We have shown that the autonomic dysfunction of diabetes is part of a complex reflex derangement, relating the cardiovascular (low BRS) to the respiratory control (inadequate, not enhanced hypoxic chemoreflex and increase in hypercapnic chemoreflex).

T1D showed to be not only "hypoxic" at rest, but also with a reduced sensitivity to hypoxia which was partially compensated by a stimulation of central chemoreflex, through sympathetic activation that reduced BRS and autonomic function tests as well (normally interpreted as "neuropathy"). We show in the present study that what is normally called "autonomic neuropathy" could be in many cases a functional condition of sympathetic activation, driven by many factors, one of which seems to be resting hypoxia. Our data provide support to the hypothesis that techniques or drugs capable of increasing the sensitivity to or relieve hypoxia could be potentially helpful in improving the autonomic dysfunction and ultimately prevent diabetic complications.

\section{Conflict of interest}

No potential conflicts of interest relevant to this article were reported.

\section{Author contributions}

L.B. (1st author), C.P., A.R., C.G., P.F., P.DC., P.P., R.P, drafted the manuscript and researched data. L.B. (senior author) developed the study concept and design, contributed to interpretation and analysis, edited and revised the manuscript; he had full access to all the data in the study and takes responsibility for the integrity of the data and the accuracy of the data analysis.

\section{Acknowledgments}

The study was supported by University of Pavia, IRCCS Fondazione S. Maugeri and Folkhälsan Research Center (FinnDiane Study Group). Parts of this study were presented in part at the diabetic neuropathy study group of the European Association for the Study of Diabetes (NEURODIAB) 2015 Annual Meeting in Elsinore, Denmark, 11-13 September 2015, and in part at the 51st annual meeting of the European Association for the Study of Diabetes (EASD) in Stockholm, Sweden, 14-18 September 2015.

\section{References}

[1] R.E. Maser, B.D. Mitchell, A.I. Vinik, R. Freeman, The association between cardiovascular autonomic neuropathy and mortality in individuals with diabetes: a metaanalysis, Diabetes Care 26 (6) (Jun 2003) 1895-1901.

[2] A. Frattola, G. Parati, P. Gamba, et al., Time and frequency domain estimates of spontaneous baroreflex sensitivity provide early detection of autonomic dysfunction in diabetes mellitus, Diabetologia 40 (12) (Dec 1997) 1470-1475.

[3] M. Ducher, C. Cerutti, M.P. Gustin, et al., Noninvasive exploration of cardiac autonomic neuropathy. Four reliable methods for diabetes? Diabetes Care 22 (3) (Mar 1999) 388-393.

[4] M.T. La Rovere, J.T. Bigger Jr., F.I. Marcus, A. Mortara, P.J. Schwartz, Baroreflex sensitivity and heart-rate variability in prediction of total cardiac mortality after myocardial infarction. ATRAMI (Autonomic Tone and Reflexes After Myocardial Infarction) Investigators, Lancet 351 (9101) (Feb 14 1998) 478-484.

[5] L. Bernardi, V. Spallone, M. Stevens, et al. Methods of investigation for cardiac autonomic dysfunction in human research studies. Toronto Consensus Panel on diabetic neuropathy, Diabetes Metab. Res. Rev. 27 (7) (Oct 2011) 654-664.

[6] M. Rosengård-Bärlund, L. Bernardi, J. Fagerudd, et al., FinnDiane Study Group, Early autonomic dysfunction in type 1 diabetes: a reversible disorder? Diabetologia 52 (6) (Jun 2009) 1164-1172.

[7] P. Esposito, R. Mereu, G. De Barbieri, et al., Trained breathing-induced oxygenation acutely reverses cardiovascular autonomic dysfunction in patients with type 2 diabetes and renal disease, Acta Diabetol. (May 9 2015)

[8] P. Ponikowski, T.P. Chua, M. Piepoli, et al., Augmented peripheral chemosensitivity as a potential input to baroreflex impairment and autonomic imbalance in chronic heart failure, Circulation 96 (8) (Oct 21 1997) 2586-2594.

[9] A.J. Coats, S. Adamopoulos, A. Radaelli, et al., Controlled trial of physical training in chronic heart failure. Exercise performance, hemodynamics, ventilation, and autonomic function, Circulation 85 (6) (Jun 1992) 2119-2131.

[10] L. Bernardi, M. Hilz, B. Stemper, C. Passino, G. Welsch, F.B. Axelrod, Respiratory and cerebrovascular responses to hypoxia and hypercapnia in familial dysautonomia Am. J. Respir. Crit. Care Med. 167 (2) (Jan 15 2003) 141-149.

[11] C. Tantucci, L. Scionti, P. Bottini, et al., Influence of autonomic neuropathy of different severities on the hypercapnic drive to breathing in diabetic patients, Chest 112 (1) (Jul 1997) 145-153.

[12] C.J. Weisbrod, P.R. Eastwood, G. O'Driscoll, D.J. Green, Abnormal ventilatory responses to hypoxia in type 2 diabetes, Diabet. Med. 22 (5) (May 2005) 563-568.

[13] M. Nishimura, K. Miyamoto, A. Suzuki, et al., Ventilatory and heart rate responses to hypoxia and hypercapnia in patients with diabetes mellitus, Thorax 44 (4) (Apr 1989) 251-257

[14] O. Kemmotsu, M. Ueda, H. Otsuka, et al., Blood pressure measurement by arterial tonometry in controlled hypotension, Anesth. Analg. 73 (1) (Jul 1991) 54-58. 
[15] Spallone, et al., Cardiovascular autonomic neuropathy in diabetes: clinical impact, assessment, diagnosis, and management, Diabetes Metab. Res. Rev. 27 (2011) 639-653.

[16] L. Bernardi, A. Schneider, L. Pomidori, E. Paolucci, A. Cogo, Hypoxic ventilatory response in successful extreme altitude climbers, Eur. Respir. J. 27 (1) (Jan 2006) 165-171.

[17] T. Haider, G. Casucci, T. Linser, et al., Interval hypoxic training improves autonomic cardiovascular and respiratory control in patients with mild chronic obstructive pulmonary disease, J. Hypertens. 27 (8) (Aug 2009) 1648-1654.

[18] D. Laude, J.L. Elghozi, A. Girard, et al., Comparison of various techniques used to estimate spontaneous baroreflex sensitivity (the EuroBaVar study), Am. J. Physiol. Regul. Integr. Comp. Physiol. 286 (1) (Jan 2004) R226-R231.

[19] L. Bernardi, G. De Barbieri, M. Rosengård-Bärlund, V.P. Mäkinen, C. Porta, P.H. Groop, New method to measure and improve consistency of baroreflex sensitivity values, Clin. Auton. Res. 20 (6) (Dec 2010) 353-361.

[21] L.J. Pu, Y. Shen, L. Lu, R.Y. Zhang, Q. Zhang, W.F. Shen, Increased blood glycohemoglobin A1c levels lead to overestimation of arterial oxygen saturation by pulse oximetry in patients with type 2 diabetes, Cardiovasc. Diabetol. 11 (Sep 17 2012) 110

[22] C.M. Wheatley, J.C. Baldi, N.A. Cassuto, W.T. Foxx-Lupo, E.M. Snyder, Glycemic control influences lung membrane diffusion and oxygen saturation in exercise-trained subjects with type 1 diabetes: alveolar-capillary membrane conductance in type 1 diabetes, Eur. J. Appl. Physiol. 111 (3) (Mar 2011) 567-578.

[23] O.L Klein, J.A Krishnan, S. Glick, LJ. Smith Systematic review of the association between lung function and type 2 diabetes mellitus, Diabet. Med. 27 (9) (Sep 2010) 977-987.

[24] D. Popov, M. Hasu, G. Costache, D. Stern, M. Simionescu, Capillary and aortic endothelia interact in situ with non-enzymatically glycated albumin and develop specific alterations in early experimental diabetes, Acta Diabetol. 34 (1997) 285-293.

[25] W.W. Chance, C. Rhee, C. Yilmaz, et al., Diminished alveolar microvascular reserves in type 2 diabetes reflect systemic microangiopathy, Diabetes Care 31 (8) (Aug 2008) 1596-1601.

[26] R.J. Hancox, R. Poulton, J.M. Greene, et al., Systemic inflammation and lung function in young adults, Thorax 62 (2007) 1064-1068.

[27] J.G. Williams, A.I. Morris, R.C. Hayter, C.M. Ogilvie, Respiratory responses of diabetics to hypoxia, hypercapnea and exercise, Thorax 39 (1984) 529-534.

[28] C.R. Hamlin, R.R. Kohn, J.H. Luschin, Apparent accelerated aging of human collagen in diabetes mellitus, Diabetes 24 (1975) 902-904.

[29] N. Cheng, W. Cai, M. Jiang, Effect of hypoxia on blood glucose, hormones, and insulin receptor functions in newborn calves, Pediatr. Res. 41 (1997) 852-856.

[30] A. Iozzo, P. Cavallo-Perin, G. Cardellino, R. Garbagni, Alveolo-arterial gradients of $\mathrm{O}_{2}$ and $\mathrm{CO}_{2}$ in hyperlipidemic subjects, Respiration 43 (2) (1982) 95-100.

[31] R.N. Aurora, N.M. Punjabi, Obstructive sleep apnoea and type 2 diabetes mellitus: bidirectional association, Lancet Respir. Med. 1 (4) (Jun 2013) 329-338.

[32] C. Greco, V. Spallone, Obstructive sleep apnoea syndrome and diabetes. Fortuitous association or interaction? Curr. Diabetes Rev. 12 (2) (2015) 129-155.

[33] S. Choudhury, S. Taheri, Obstructive sleep apnoea and type 2 diabetes: whose disease is it anyway? Pract. Diabetes Int. 28 (2011) 183-186.
[34] L.R. Solomon, K. Cohen, Erythrocyte $\mathrm{O}_{2}$ transport and metabolism and effects of vitamin B6 therapy in type II diabetes mellitus, Diabetes 38 (7) (Jul 1989) 881-886.

[35] M.C. De Rosa, M.T. Sanna, I. Messana, et al., Glycated human hemoglobin (HbA1c): functional characteristics and molecular modeling studies, Biophys. Chem. 72 (3) (Jun 9 1998) 323-335.

[36] S.B. Catrina, K. Okamoto, T. Pereira, K. Brismar, L. Poellinger, Hyperglycemia regulates hypoxia-inducible factor-1alpha protein stability and function, Diabetes 53 (12) (Dec 2004) 3226-3232.

[37] C.F. Bento, R. Fernandes, J. Ramalho, et al., The chaperone-dependent ubiquitin ligase CHIP targets HIF- $1 \alpha$ for degradation in the presence of methylglyoxal, PLoS One 5 (11) (Nov 29 2010), e15062.

[38] C.F. Bento, P. Pereira, Regulation of hypoxia-inducible factor 1 and the loss of the cellular response to hypoxia in diabetes, Diabetologia 54 (8) (Aug 2011) 1946-1956.

[39] V.K. Somers, A.L. Mark, D.C. Zavala, F.M. Abboud, Contrasting effects of hypoxia and hypercapnia on ventilation and sympathetic activity in humans, J. Appl. Physiol. 67 (5) (Nov 1985) 2101-2106

[40] L. Bernardi, M. Rosengård-Bärlund, A. Sandelin, V.P. Mäkinen, C. Forsblom, P.H. Groop, FinnDiane Study Group, Short-term oxygen administration restores blunted baroreflex sensitivity in patients with type 1 diabetes, Diabetologia 54 (8) (Aug 2011) 2164-2173.

[41] V.K. Somers, A.L. Mark, F.M. Abboud, Interaction of baroreceptor and chemoreceptor reflex control of sympathetic nerve activity in normal humans, J. Clin. Invest. 87 (6) (Jun 1991) 1953-1957.

[42] D.P. Francis, P. Ponikowski, AJS. Coats, Chemoreflex-baroreflex interactions in cardiovascular disease, in: D.T. Bradley, J.S. Floras (Eds.), Sleep Apnea. Implications in Cardiovascular and Cerebrovascular Disease, Dekker, New York, NY 2000, pp. 33-56.

[43] K. Narkiewicz, C.A. Pesek, P.J. van de Borne, M. Kato, V.K. Somers, Enhanced sympathetic and ventilatory responses to central chemoreflex activation in heart failure, Circulation 100 (3) (Jul 20 1999) 262-267.

[44] M. Guazzi, R. Brambilla, G. Pontone, P. Agostoni, M.D. Guazzi, Effect of non-insulindependent diabetes mellitus on pulmonary function and exercise tolerance in chronic congestive heart failure, Am. J. Cardiol. 89 (2) (Jan 15 2002) 191-197.

[45] T. Miyata, S. Takizawa, C. van Ypersele de Strihou, Hypoxia. Intracellular sensors for oxygen and oxidative stress: novel therapeutic targets, Am. J. Physiol. Cell Physiol. 300 (2) (Feb 2011) C226-C231.

[46] K. Stamatakis, M.H. Sanders, B. Caffo, et al., Fasting glycemia in sleep disordered breathing: lowering the threshold on oxyhemoglobin desaturation, Sleep 31 (7) (Jul 2008) 1018-1024.

[47] G.B. Arden, S. Sivaprasad, Hypoxia and oxidative stress in the causation of diabetic retinopathy, Curr. Diabetes Rev. 7 (5) (Sep 2011) 291-304.

[48] T. Miyata, C.Y. de Strihou, Diabetic nephropathy: a disorder of oxygen metabolism? Nat. Rev. Nephrol. 6 (2) (Feb 2010) 83-95.

[49] H. Xiao, Z. Gu, G. Wang, T. Zhao, The possible mechanisms underlying the impairment of HIF-1 $\alpha$ pathway signaling in hyperglycemia and the beneficial effects of certain therapies, Int. J. Med. Sci. 10 (10) (Aug 22 2013) 1412-1421. 